\title{
Retroperitoneum ganglioneuroma: imaging features and surgical outcomes of 35 cases at a Chinese Institution
}

\author{
Qian-Wen Zhang, Tao Song, Pan-Pan Yang and Qiang Hao*
}

\begin{abstract}
Background: The preoperative evaluation is crucial for diagnosis and surgical plan of retroperitoneum ganglioneuroma (GN). In this study, we reviewed a relatively large series of histopathological proved retroperitoneum GN cases, summarized the imaging features and further depicted risk factors of increased surgical blood loss.

Methods: A total of 35 (18 male, 17 female) patients were retrospectively enrolled from January 2012 to June 2019 at our institution. Among them, 24 patients had undergone CT scans and 19 patients had undergone MR examination before treatment. The clinical and radiological features were analyzed and the relationships between image features and surgical blood loss were evaluated.

Results: The media age of the involved 35 patients was 40 years (range, 14-66 years). The histological tumor size was $10.12 \pm 4.56 \mathrm{~cm}$ for average. Retroperitoneum GN was relatively low density on unenhanced CT images and showed delayed progressive enhancement on enhanced CT and MR images. The whorled sign could be seen in 14 patients. The vessel encasement sign could be found in 17 patients. Univariate analysis revealed maximal tumor size measured on axial image, maximal tumor size measured on coronal image, encasing one or both renal pedicles, encasing the aorta and/or vena cava and whorled sign on MRI showed significant difference between the blood loss $\geq 400 \mathrm{ml}$ and blood loss $<400 \mathrm{ml}$ group. Logistic regression further detected that maximal tumor size measured on axial images (OR: 1.12; 95\% Cl: 1.02-1.24; $P=0.023$ ) and encasing one or both renal pedicles (OR: 22.39; 95\% Cl: 1.35-372.99; $P=0.030$ ) were independently correlated with surgical blood loss.
\end{abstract}

Conclusions: Preoperative CT and MR imaging analysis was valuable for both diagnosis and surgical risk prediction of retroperitoneum GN.

Keywords: Ganglioneuroma, Retroperitoneum, Computed tomography, Magnetic resonance imaging, Surgery

\section{Background}

Ganglioneuroma (GN) is a rare benign tumor which originates from neural crest cells. It is mainly composed of mature Schwann cells, ganglion cells and nerve fibers. GN may arise anywhere along the paravertebral sympathetic plexus. The retroperitoneum and posterior

*Correspondence: hq13386277876@126.com; haoqiang@189.cn Department of Radiology, Changhai Hospital, The Navy Medical University (Second Military Medical University), 168 Changhai Road, Shanghai, China mediastinum are the two most common locations of GN [1-4]. Although GN is regarded as an uncommon tumor, more and more GNs have been detected with the dramatically increased use of computed tomography (CT) and magnetic resonance imaging (MRI). Though GNs are benign tumors, they may cause pain and compression symptoms and recurrence or malignant transformation has been reported $[2,5,6]$. Due to these characteristics, surgical resections and postoperative monitoring are recommended for GN patients. 
There have been several studies describing the radiological appearances of GN [2, 7-16], but the reported case series are relatively small. To date, few studies have focused on the primary non-adrenal retroperitoneum GN. The precise diagnosis of non-adrenal retroperitoneum GN prior to surgery remains challenging. The non-invasive diagnosis of GN is important, because the surgical strategy and surgical approach can be different for benign and malignant tumors. Prior to the surgical procedure, CT and MR images can demonstrate important features of the tumors and help to narrow the differential diagnosis. Moreover, $\mathrm{CT}$ and $\mathrm{MR}$ images enable a multiplanar evaluation revealing the exact localization of the lesion and could heip to accurately evaluate the association of the mass with adjacent structure. Therefore, preoperative imaging of GNs could substantially facilitate preoperative planning. In this study, we reviewed a relatively large series of histopathological proved non-adrenal retroperitoneum GN cases at our institution and interpreted the CT and MRI features of them. Furthermore, we analyzed risk factors of increased surgical blood loss based on radiographic images for the first time.

\section{Methods}

This study was a single-center retrospective study approved by the Committee on Ethics of Medicine of Changhai hospital and the study was carried out in accordance and relevant guidelines and regulations. The requirement to obtain written informed consent was waived by the Committee on Ethics of Medicine of Changhai hospital. Computerized patient record systems and the laboratory, pathology and radiology databases were searched from January 2012 to June 2019. The inclusion criteria were as follows: pathologically proven retroperitoneum GN; undergone contrast-enhanced $\mathrm{CT}$ or MRI before surgery. The exclusion criteria were: adrenal GN cases; absence of a presurgical contrast-enhanced CT or MRI record in our hospital; not undergoing surgical resection of tumors. Follow-up data were obtained by searching medical records in our hospital and making phone calls to the patients. The written informed consents were obtained from all patients.

\section{Patients}

A total of 35 patients (18 male, 17 female) were pathologically diagnosed with retroperitoneum GN during the 7 -years-period in our hospital. Their age ranged from 14 to 66 (median, 40 years). All of them were treated operatively. The mean time interval from preoperative imaging to surgery was 5 days (range, $0-27$ days).

\section{Modalities}

Among them, 24 patients had undergone CT scans and 19 patients had undergone MR examination before treatment. The CT scans were carried on by a 320-multidetector row CT system (Toshiba Medical Systems, Tokyo, Japan). The CT scan parameters were as follows: $120 \mathrm{kV}$, 150 effective mAs, a matrix of $350 \times 350$, and a gantry rotation time of $0.5 \mathrm{~s}$. The intravenous iodinated contrast agent (Iopamiro, Bracco Sine Pharmaceuticals, Shanghai, China) was administered for contrast media enhancement. The contrast-enhanced CT scans were performed in arterial (20-25 s) and venous (60-70 s) phases after the contrast agent injection. MR imaging was performed by a 1.5 T MR system (GE Medical System, USA) with a body coil. The MR protocol contained horizontal T1 (repetition time (TR) $2.58 \mathrm{~ms}$, echo time (TE) $1.18 \mathrm{~ms}$ ) and T2 weighted (TR $6316 \mathrm{~ms}$, TE $87 \mathrm{~ms}$ ) images, coronal T2 weighted images (TR $7000 \mathrm{~ms}$, TE $1230 \sim 1270 \mathrm{~ms}$ ) and diffusion-weighted imaging (DWI) (TR $5000 \mathrm{~ms}$, TE of $80 \mathrm{~ms}, \mathrm{~b}=800$ ). Images were obtained with a field of view of $440 \times 440 \mathrm{~mm}$, an image matrix of $224 \times 270$, and a slice thickness of $5 \mathrm{~mm}$. Gadolinium-diethylenetriamine pantaacetic acid (Gd-DTPA, Magnevist, Berlin, Germany) was intravenously administrated for contrast media enhancement. The delayed time was 30 and $70 \mathrm{~s}$ after injection of contrast agent.

\section{Image analysis}

The images were reviewed by two experienced radiologists (Zhang \& Yang) independently, and discrepancies were resolved by consensus. The two readers were blinded to the operation records. The following radiological characteristics were assessed: tumor size (maximal diameter measured on axial and coronal 2D images), shape (round, oval or irregular), calcification (present or absent), density (CT)/ signal (MR) features, pre-contrast appearance (homogeneous or heterogeneous), the pattern of enhancement, specific signs including vessel encasement and whorled sign. The vessel encasement sign represented that the tumor showed the trend to surround major blood vessels $\left(>180^{\circ}\right)$. The vessel encasement signs are categorized into 3 types: tumor encasing the origin of the coeliac axis, and/or of the superior mesenteric artery; tumor encasing one or both renal pedicles; tumor encasing the aorta and/or vena cava $[17,18]$. The whorled sign was evaluated on MR T2-weighted images. The manifestation of the whorled sign was that the tumor was predominantly high intensity on T2-weighted image and an interlaced or nodular low-signal part can be seen within the tumor (Fig. 1). The whorled sign corresponded to the microscopic interlacing patterns of Schwann cells and collagen fibers within the tumor $[10,19]$. All the 

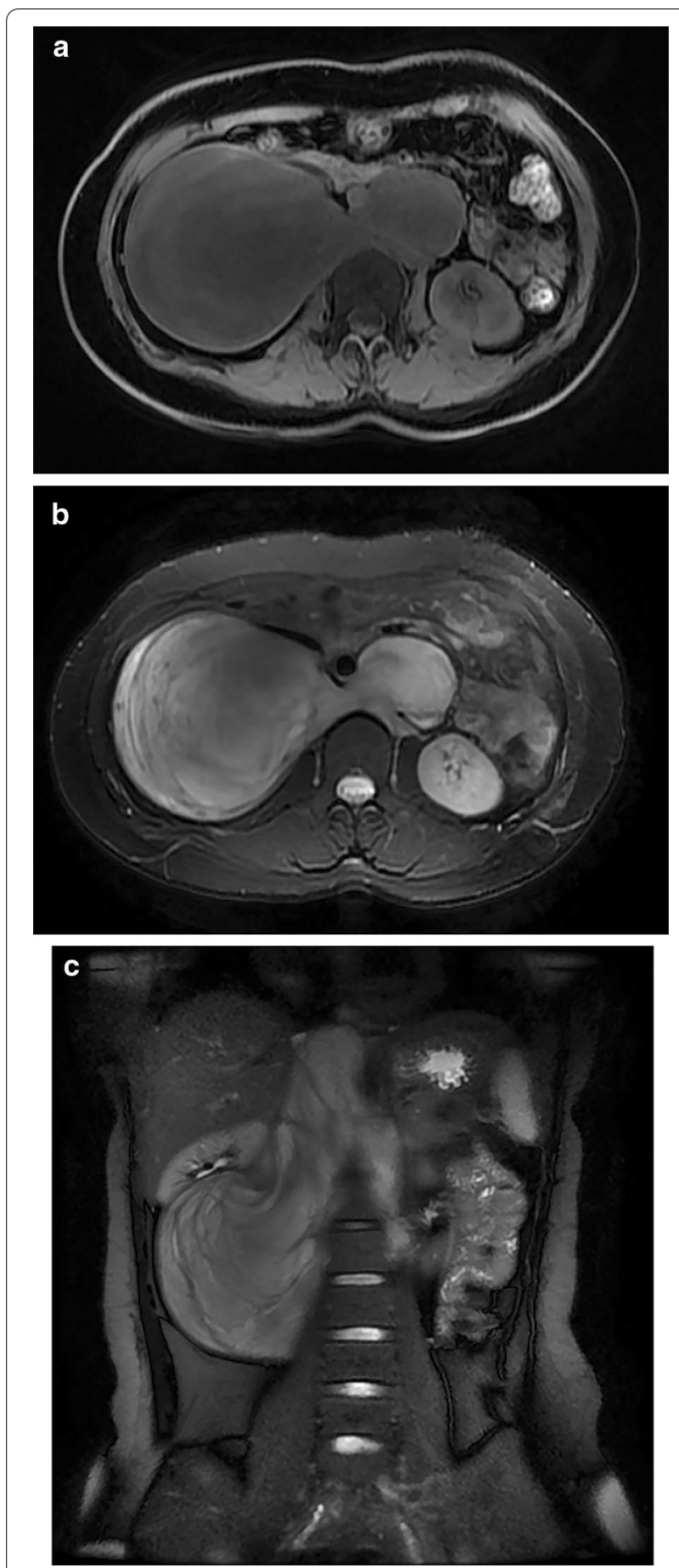

Fig. 1 MR image of a 23-years-old female (patient no.25). The retroperitoneum ganglioneuroma was incidentally detected by a health check-up CT examination. a T1-weighted image. $\mathbf{b}$ axial T2-weighted image. c. coronal T2-weighted image. The whorled sign of retroperitoneum ganglioneuroma could be observed on T2-weighted image $(\mathbf{b}, \mathbf{c})$. The large amount of myxoid stroma presented predominantly high signal intensity on T2-weighted images and the cellular components including Schwann cells and ganglions may be responsible for the interlaced or nodular low signal intensity clinical details, laboratory, pathological and follow-up data were also documented.

\section{Statistical analysis}

The statistical analyses were performed with Predictive Analysis Software 18.0 (IBM, Armonk, New York, USA). Two-tailed $P$ values were computed and a $P$ value of less than 0.05 was considered to be statistically significant. All data were checked up with the Kolmogorov-Smirnov test to assess the normality. Continuous variables were showed as mean \pm standard deviation (SD), while categorical variables presented as numbers or percentages. Differences between groups were assessed using the independent samples $t$ test for continuous variables if they are conformed to the normal distribution and the Mann-Whitney U-test for those were not normally distributed. Logistic regression analysis was performed to examine associations between characteristics and surgical outcomes.

\section{Results}

\section{Basic characteristics}

Thirty-five retroperitoneum GN patients were enrolled in this study, including 18 male and 17 female patients. The baseline characteristics were displayed in Table 1, including age, gender, histological tumor size, symptoms, surgical blood loss, postoperative hospital stay. In detail, the mean age of the involved patients was 40 years, ranging from 14 to 66 years. The documented histological tumor size was $10.12 \mathrm{~cm} \pm 4.56 \mathrm{~cm}$ for average. As for clinical manifestations, the tumor was asymptomatic in 25 patients (71.4\% of the cases). The remaining 10 patients (28.6\% of the cases) suffered from abdominal pain or discomfort $(\mathrm{n}=7)$ and back pain $(\mathrm{n}=3)$. Among the 25 asymptomatic patients, 21 cases were incidentally discovered by health check-ups, and 4 cases were detected when checking for other diseases such as cholecystitis, ureteral calculi and lumbar fracture. The adrenal hormonal levels of all the patients were within the normal range.

\section{Image findings}

Twenty-four patients had undergone CT scans and 19 patients had undergone MR imaging. Eight patients had both CT and MR records. The imaging features were described in Tables 2 and 3 separately. In 17 cases, tumors tend to surround major blood vessels but without invasion or occlusion. None of the cases showed evidence of regional lymph node enlargement and visceral metastasis.

Twenty-four patients had undergone enhanced CT scans (Table 2). GNs presented hypodense on pre-contrast CT images, with a mean attenuation density of $32.11 \mathrm{Hu}$ (range, 19.4-53.2Hu). They were homogenous 
Table 1 Clinical and demographic characteristics of the 35 cases

\begin{tabular}{|c|c|c|c|}
\hline Variables & No. of patients & Mean \pm SD & Median (range) \\
\hline \multicolumn{4}{|l|}{ Gender } \\
\hline Male & $18(51.4 \%)$ & & \\
\hline Female & $17(48.6 \%)$ & & \\
\hline Age (years) & & $40.83 \pm 12.96$ & $40(14-66)$ \\
\hline \multicolumn{4}{|l|}{ Symptoms } \\
\hline Incidentally detected & $25(71.4 \%)$ & & \\
\hline Abdominal pain or discomfort & $7(20.0 \%)$ & & \\
\hline Back pain & $3(8.6 \%)$ & & \\
\hline \multicolumn{4}{|l|}{ Adrenal hormonal secretion } \\
\hline Normal & $35(100 \%)$ & & \\
\hline Abnormal & 0 & & \\
\hline Histological tumor size (cm) & & $10.12 \pm 4.56$ & $9.5(4-23)$ \\
\hline \multicolumn{4}{|l|}{ Surgical blood loss } \\
\hline$\geq 400 \mathrm{ml}$ & 15 (42.9\%) & & \\
\hline$<400 \mathrm{ml}$ & $20(57.1 \%)$ & & \\
\hline Postoperative hospital stays (days) & & $7.03 \pm 3.23$ & $6(3-18)$ \\
\hline
\end{tabular}

in 15 of 24 patients and heterogeneous in the remaining 9 patients. Punctate calcifications were found in 8 cases. After contrast, the progressive delayed enhancement was seen in 20 of 24 cases, while slightly contrast washout was observed in one case. In 3 cases, the tumor did not enhance at all. The enhancement pattern was shown in Fig. 2.

Nineteen patients had undergone enhanced MR imaging (Table 3). GNs revealed hypointense signals on T1-weighted images and heterogeneous hyperintense signals on T2-weighted images in all 19 patients. The whorled appearance was observed in 14 patients. GNs presented delayed heterogeneous enhancement in 12 patients and relatively homogenous enhancement in 6 patients. In one case, no enhancement was seen.

\section{Surgical findings and outcomes}

Complete tumor resection was carried out in 34 cases (97.1\%), and partial excision in 1 patient (2.9\%) because the patient refused to take risks of nephrectomy. One patient underwent distal pancreatectomy and one underwent nephrectomy because of tumor adhesion. The median blood loss during surgery was $200 \mathrm{ml}$, ranging from $20 \mathrm{ml}$ to $4000 \mathrm{ml}$. The estimated blood loss was over or equal to $400 \mathrm{ml}$ in 15 cases and less than $400 \mathrm{ml}$ in 20 cases. Severe surgical complications occurred in one patient (patient no.13) because of postoperative rebleeding that led to hypoperfusion. The patient died of multiple system organ failures on the 18th postoperative day. Follow-up data were available for 28 patients and the median follow-up duration was 22 months (range, 10-81 months). No recurrence or metastasis was found in these patients. Six patients were lost of follow-up because of the wrong phone number.

\section{Risk factors of increased blood loss during surgery}

Maximal tumor size measured on axial image, maximal tumor size measured on coronal image, calcification, encasing one or both renal pedicles, encasing the aorta and/or vena cava and whorled sign on MRI showed significant difference between the blood loss $\geq 400 \mathrm{ml}$ and blood loss $<400 \mathrm{ml}$ group (Table $4 \mathrm{~A}, \mathrm{~B}$ ). Logistic regression revealed that maximal tumor size measured on axial images (OR: 1.12; 95\% CI: $1.02-1.24 ; P=0.023$ ) and encasing one or both renal pedicles (OR: 22.39; 95\% CI: 1.35-372.99; $P=0.030)$ were independently correlated with surgical blood loss (Table 5). Age, gender, encasing the origin of celiac axis, and/or of the superior mesenteric artery and $\mathrm{CT}$ value demonstrated no significant difference between the two groups.

\section{Discussion}

To our knowledge, this study is the largest case series of retroperitoneum GNs and this was the first study evaluating imaging-based risk factors of increased surgical blood loss. In this case series, retroperitoneum GNs were recognized to be hormonally inactive, mostly incidentally discovered and with satisfying outcomes after surgery. Since GNs are mostly hormone-silent and asymptomatic and retroperitoneum space is deep and extensive, they can be huge when detected. These findings were consistent with previous studies $[1,4,20]$. The gender incidence of GN varies in literature [7, 8, 14, 21, 22]. In our 


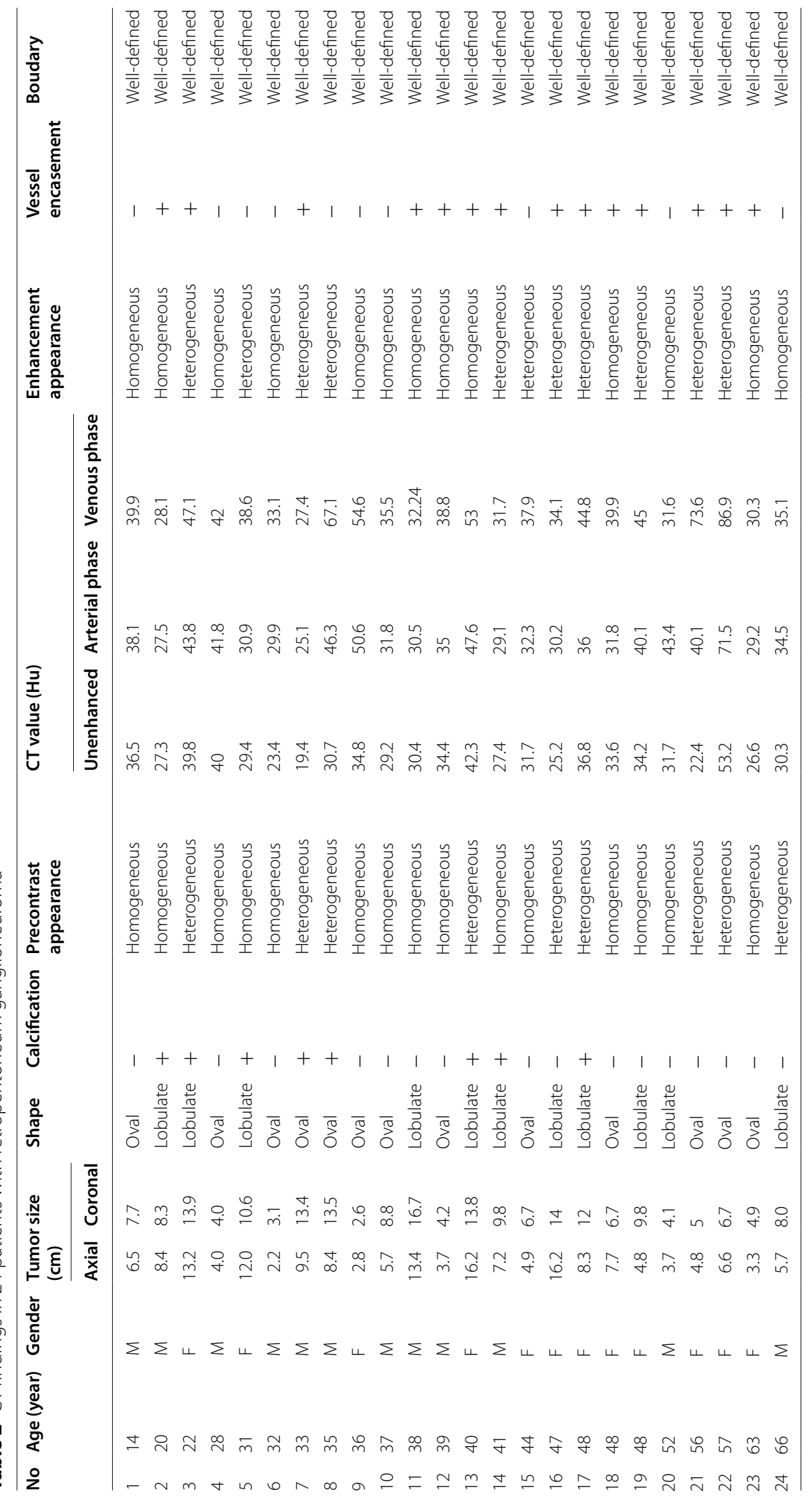




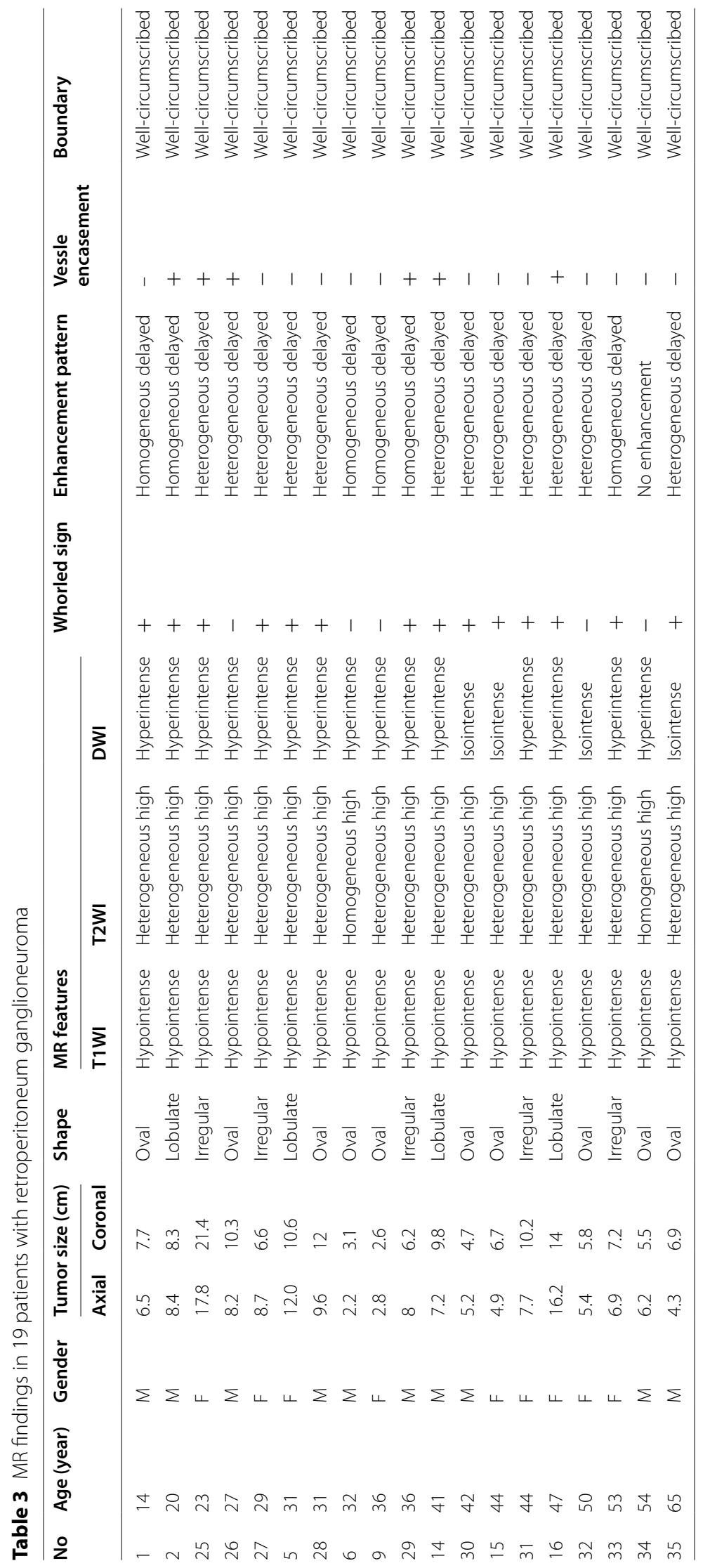




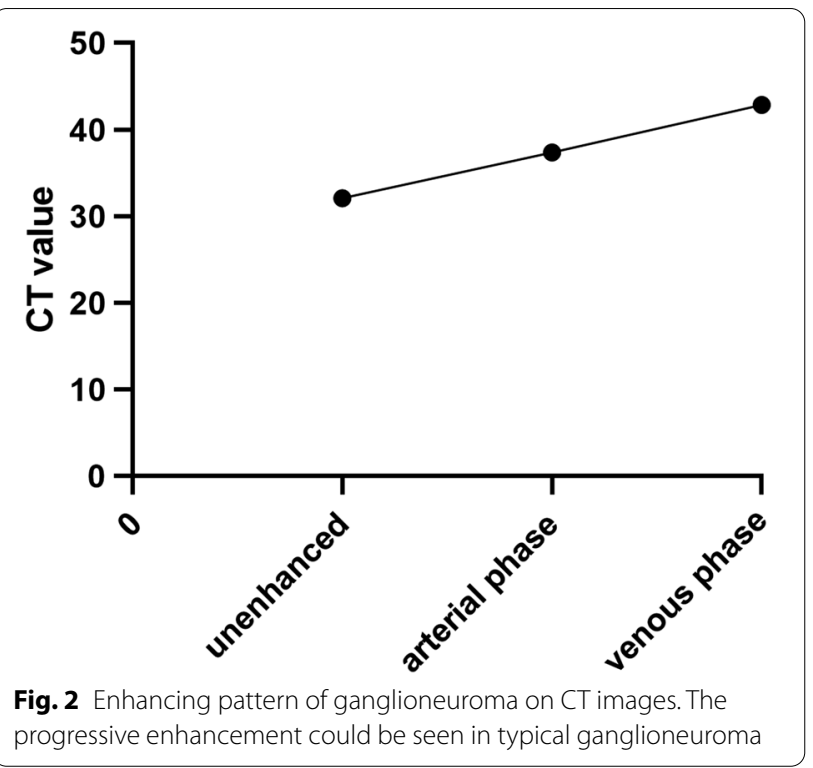

experience, we found a similar GN morbidity between females and males.

Retroperitoneum GNs in our study displayed as welldefined hypodense masses on unenhanced CT images, mostly homogenous. Punctate calcifications were found in $33.3 \%$ cases. The sight or moderate progressive enhancement was observed in most patients. On MR images, GNs often presented to be hypointense on T1-weighted images, heterogeneous hyperintense on T2-weighted images and hyperintense on DWI images.
These imaging features were similar to previous literature reports $[1,3,4,8,9,11,13,14,19,23]$. The whorled sign, as previously reported, was considered as a specific sign of GN $[9,10,19]$. In our study, the whorled sign could be seen in $73.7 \%$ patients and it was in accordance with the pathological components of GN. The large amount of myxoid stroma presented predominantly high signal intensity on T2-weighted images. The cellular components, including Schwann cells and ganglions, may be responsible for the interlaced or nodular low signal intensity $[1,3,7]$. Interestingly, retroperitoneum GNs tend to extend along the inter-vessel space and partially or wholly surround major blood vessels, with nearly half of the patients (17/35) presented with vessel encasement signs. Under this circumstance, the GNs could be confused with malignant tumors.

The differential diagnosis of GN includes many malignant and benign tumors, including neuroblastoma (NB), ganglioneuroblastoma (GNB), schwannoma, lymphangioma and so on. NB, GNB and GN originate from the

Table 5 Logistic regression analysis on the risk factors of blood loss $\geq 400 \mathrm{ml}$ during surgery

\begin{tabular}{lcl}
\hline Variables & OR (95\%Cl) & P value \\
\hline Maximal diameter on axial images & $1.12(1.02-1.24)$ & 0.023 \\
Encasing one or both renal pedicles & $22.39(1.35-372.99)$ & 0.030 \\
\hline
\end{tabular}

Table 4 Comparison of Clinical and imaging parameters of GNs based on blood loss

\begin{tabular}{|c|c|c|c|c|c|c|c|c|c|c|c|c|}
\hline \multirow[t]{2}{*}{ Variables } & \multicolumn{2}{|l|}{ Gender } & \multicolumn{2}{|c|}{$\begin{array}{l}\text { Encasing the } \\
\text { aorta and/or } \\
\text { vena cava }\end{array}$} & \multicolumn{2}{|c|}{$\begin{array}{l}\text { Encasing one } \\
\text { or both renal } \\
\text { pedicles }\end{array}$} & \multicolumn{2}{|c|}{$\begin{array}{l}\text { Encasing the } \\
\text { origin of CA and/ } \\
\text { or SMA }\end{array}$} & \multicolumn{2}{|c|}{ Calcification } & \multicolumn{2}{|c|}{ Whorled sign } \\
\hline & Male & Female & Yes & No & Yes & No & Yes & No & Yes & No & Yes & No \\
\hline \multicolumn{13}{|l|}{$A$} \\
\hline Blood loss $<400 \mathrm{ml}$ & 12 & 8 & 4 & 16 & 2 & 18 & 1 & 19 & 1 & 12 & 6 & 5 \\
\hline Blood loss $\geq 400 \mathrm{ml}$ & 6 & 9 & 8 & 7 & 11 & 4 & 3 & 12 & 7 & 4 & 8 & 0 \\
\hline Fisher exact test & 1.333 & & 4.106 & & 14.30 & & 1.851 & & 8.04 & & 4.675 & \\
\hline$P$ value (2-tailed) & 0.248 & & 0.043 & & $<0.0$ & & 0.174 & & 0.00 & & 0.031 & \\
\hline \multirow[t]{2}{*}{ Variables } & \multirow{2}{*}{\multicolumn{2}{|c|}{ Age }} & \multirow{2}{*}{\multicolumn{2}{|c|}{$\begin{array}{l}\text { Maximal diameter } \\
\text { on axial images }\end{array}$}} & \multirow{2}{*}{\multicolumn{2}{|c|}{$\begin{array}{l}\text { Maximal diameter on } \\
\text { coronal images }\end{array}$}} & \multicolumn{6}{|c|}{ CT value } \\
\hline & & & & & & & Une & nced & Arte & hase & Veno & hase \\
\hline \multicolumn{13}{|l|}{ B } \\
\hline Blood loss < 400 ml & \multicolumn{2}{|c|}{$40.50 \pm 14.07$} & \multicolumn{2}{|l|}{$5.27 \pm 1.82$} & \multicolumn{2}{|c|}{$6.46 \pm 2.69$} & \multicolumn{2}{|c|}{$31.22 \pm 5.02$} & \multicolumn{2}{|c|}{$37.93 \pm 6.55$} & \multicolumn{2}{|c|}{$43.42 \pm 13.59$} \\
\hline Blood loss $\geq 400 \mathrm{ml}$ & \multicolumn{2}{|c|}{$37.27 \pm 10.74$} & \multicolumn{2}{|l|}{$10.77 \pm 3.72$} & \multicolumn{2}{|c|}{$11.69 \pm 4.09$} & \multicolumn{2}{|c|}{$33.16 \pm 9.41$} & \multicolumn{2}{|c|}{$36.73 \pm 13.40$} & \multicolumn{2}{|c|}{$42.17 \pm 12.90$} \\
\hline$t$ value & \multicolumn{2}{|l|}{1.430} & \multicolumn{2}{|l|}{-5.274} & \multicolumn{2}{|c|}{-4.599} & \multicolumn{2}{|c|}{-0.645} & \multicolumn{2}{|c|}{0.287} & \multicolumn{2}{|l|}{0.202} \\
\hline$P$ value (2-tailed) & \multicolumn{2}{|l|}{0.162} & \multicolumn{2}{|l|}{$<0.01$} & \multicolumn{2}{|l|}{$<0.01$} & \multicolumn{2}{|c|}{0.526} & 0.77 & & 0.842 & \\
\hline
\end{tabular}



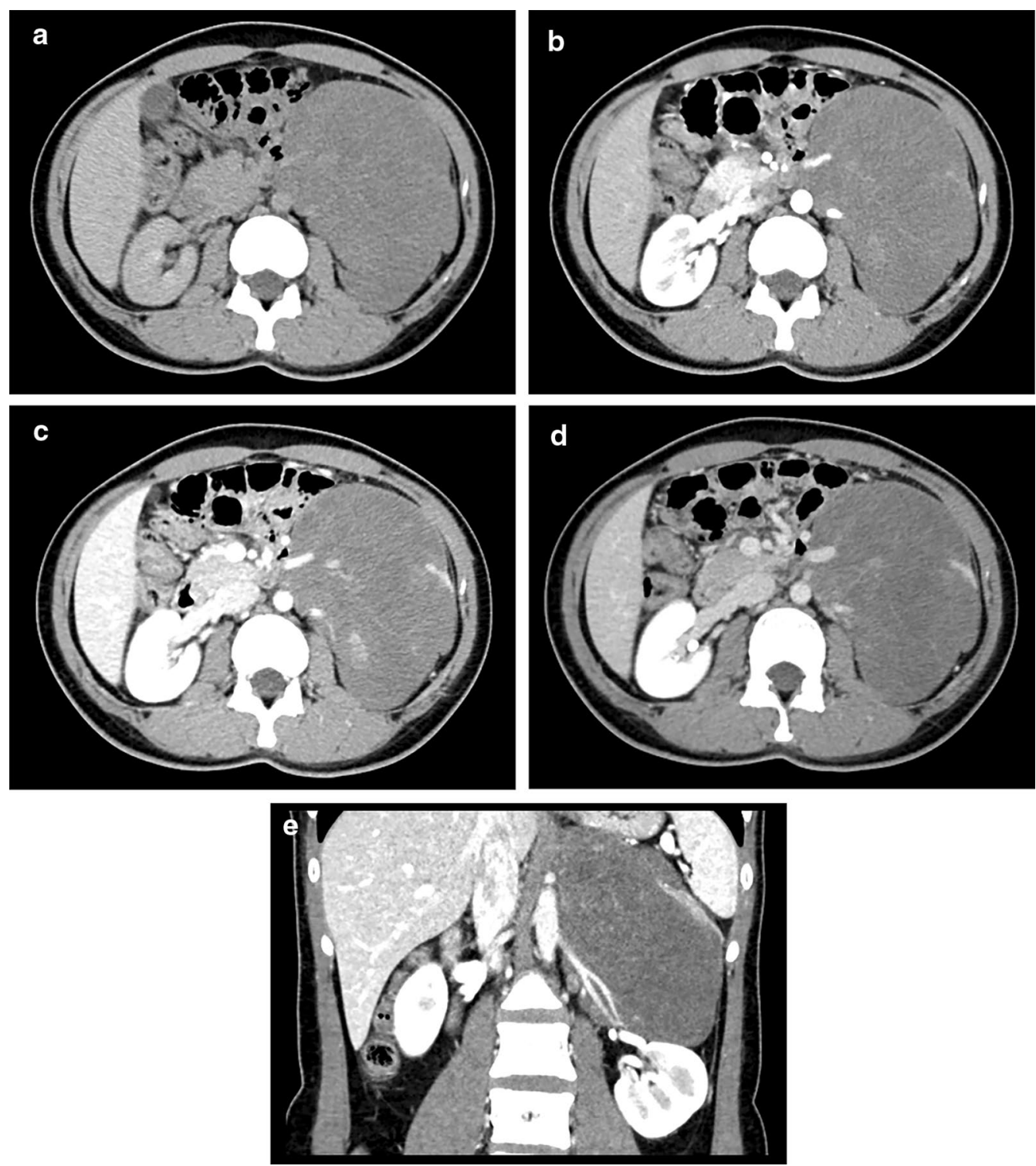

Fig. 3 CT image of a 22-years-old female (patient no.3). The retroperitoneum ganglioneuroma was incidentally detected by the health examination after college graduation. a Non-enhanced image. $\mathbf{b}$ arterial phase. $\mathbf{c}$ portal phase. $\mathbf{d}$ delayed phase. e coronal image. The tumor encased the left renal pedicle, and the patient lost $900 \mathrm{ml}$ blood during surgery

ganglion cells. The three tumors differ in their degree of cellular and extracellular maturation. NB are highly malignant lesions and GNB has intermediate malignant potential. NB are more aggressive and occur in younger patients (median age, under 2 years). NB and GNB often present as irregularly shaped, unencapsulated lesions and tend to be inhomogeneous owing to tumor necrosis and hemorrhage. They have the trend to invade adjacent organs and adjacent vessels and tend to metastasize to bone, bone marrow, liver and lymph nodes [1]. Regional invasion of paraspinal musculature and psoas may occur, and invasion of the neural foramen into the epidural space is also frequent. In our retroperitoneum GN cases, no invading of the vessels and organs was observed, which suggested benign tumors. Moreover, metastasis was rarely seen in GNs. Schwannomas arise from the nerve sheath and constitute the majority of neurogenic retroperitoneum neoplasms. They are commonly diagnosed in patients in the 2nd to 5 th decades of life. Schwannomas are composed of alternating Antony A and Antony B areas and degenerative parts [24]. Schwannomas are encapsulated masses and extend along the nerve 
course. Large schwannomas may present prominent cystic degeneration and calcification. Schwannomas have been reported to exhibit a target-like appearance, i.e., peripheral high-signal intensity and central low-signal intensity, on T2 weighted images [25]. Retroperitoneal lymphangiomas can present at any age and are common in males. They often present as unilocular or multilocular thin-walled cysts with no enhancement.

Surgical treatment is the optimal choice for the treatment of retroperitoneum GNs $[2,26]$. According to the experience of our institution, complete rection was possible for most patients. However, since GNs may adhere to tissues nearby and surround the major adjacent vascular structures [12], the resection can be complex and surgical risks should not be underestimated. In this study, the estimated blood loss was over or equal to $400 \mathrm{ml}$ in 15 cases during the operation, with the maximum blood loss as $4000 \mathrm{ml}$. A large amount of bleeding may lead to blood transfusion, even to organ ischemia-reperfusion injury, shock and death. As a result, preoperative radiological interpretations of retroperitoneum GNs are crucial. Importantly, we have found that larger tumor size measured on axial images and encasing one or both renal pedicles (Fig. 3) may lead to increased blood loss during surgery. Moreover, we have found that the maximal diameters measured on coronal 2D images of retroperitoneum GNs were more extensive than those measured on axial images in $68.6 \%(24 / 35)$ cases, which was in accordance with the potential of GNs to grow vertically from the sympathetic ganglia [2]. These findings may help the surgeon to predict surgical risk, select surgical technique, and carry out surgical treatment. Our followup data, consistent with previous studies $[15,16]$, indicated the good prognosis of retroperitoneum GNs after surgical procedure.

We acknowledged that our study had several limitations. First, this was a single-center retrospective study, which may lead to the bias of data. Also, those patients who did not receive surgery were not enrolled, which could limit the representation of our case series. Despite these limitations, we believe that our data indeed provided valuable information on retroperitoneum GN. And studies with large sample sizes will be carried out for further verification.

\section{Conclusions}

In summary, CT and MR displayed vital roles in the diagnosis and pre-operative evaluation of GNs. Though GNs are uncommon tumors, they should be taken into consideration when specific features are presented. These features are as follows: (a) relatively low density on unenhanced CT images, (b) the whorled sign on T2-weighted images, (c) the possible tendency to surround major vessels but with no narrowing, (d) the delayed progressive enhancement on enhanced CT and MR images. Preoperative images could provide image-defined risk factors for surgery. Larger tumor size measured on axial images and encasing one or both renal pedicles may lead to increased blood loss during surgery.

\section{Abbreviations \\ GN: Ganglioneuroma; CT: Computed tomography; MRI: Magnetic resonance imaging; SD: Standard deviation; SMA: Superior mesenteric artery; CA: The celiac axis; NB: Neuroblastoma; GNB: Ganglioneuroblastoma.}

\section{Acknowledgements}

Not applicable.

Authors' contributions

QWZ, TS and PPY analyzed and interpreted the patient data. QWZ and QH wrote the manuscript. All authors read and approved the final manuscript.

\section{Funding}

National Science Foundation for Scientists of China (81871485), Initial Foundation for Young Scientists of Changhai hospital (2020QNB01).

Availability of data and materials

Not applicable.

\section{Declarations}

\section{Ethics approval}

This study was approved by the Committee on Ethics of Medicine of Changhai hospital and the study was carried out in accordance and relevant guidelines and regulations.

\section{Consent to participate}

The requirement to obtain written informed consent was waived by the Committee on Ethics of Medicine of Changhai hospital.

\section{Consent for publication}

Consents for publication were obtained from all patients.

\section{Competing interests}

The authors declare that they have no competing interests.

Received: 29 March 2021 Accepted: 7 July 2021

Published online: 22 July 2021

\section{References}

1. Rha SE, Byun JY, Jung SE, Chun HJ, Lee HG, Lee JM. Neurogenic tumors in the abdomen: tumor types and imaging characteristics. Radiographics. 2003:23(1):29-43.

2. Lonergan GJ, Schwab CM, Suarez ES, Carlson CL. Neuroblastoma, ganglioneuroblastoma, and ganglioneuroma: radiologic-pathologic correlation. Radiograph Rev Publ Radiol Soc N Am. 2002;22(4):911-34.

3. Otal P, Escourrou G, Mazerolles C, Janne d'Othee B, Mezghani S, Musso S, Colombier D, Rousseau H, Joffre F. Imaging features of uncommon adrenal masses with histopathologic correlation. Radiographics. 1999;19(3):569-81.

4. Lattin GE Jr, Sturgill ED, Tujo CA, Marko J, Sanchez-Maldonado KW, Craig WD, Lack EE. From the radiologic pathology archives: Adrenal tumors and tumor-like conditions in the adult: radiologic-pathologic correlation. Radiograph Rev Publ Radiol Soc N Am. 2014;34(3):805-29.

5. Prakash V, Batanian JR, Guzman MA, Duncavage EJ, Geller TJ. Malignant transformation of a desmoplastic infantile ganglioglioma in an 
infant carrier of a nonsynonymous TP53 mutation. Pediatr Neurol. 2014;51(1):138-43.

6. Hayashi Y, Iwato M, Hasegawa M, Tachibana O, von Deimling A, Yamashita J. Malignant transformation of a gangliocytoma/ganglioglioma into a glioblastoma multiforme: a molecular genetic analysis. Case report. J Neurosurg. 2001;95(1):138-42.

7. Cai J, Zeng Y, Zheng H, Qin Y, Kaiyong T, Zhao J. Retroperitoneal ganglioneuroma in children: $\mathrm{CT}$ and MRI features with histologic correlation. Eur J Radiol. 2010;75(3):315-20.

8. Radin R, David CL, Goldfarb H, Francis IR. Adrenal and extra-adrenal retroperitoneal ganglioneuroma: imaging findings in 13 adults. Radiology. 1997;202(3):703-7.

9. Guo YK, Yang ZG, Li Y, Deng YP, Ma ES, Min PQ, Zhang XC. Uncommon adrenal masses: $\mathrm{CT}$ and MRI features with histopathologic correlation. Eur J Radiol. 2007;62(3):359-70.

10. Zhang Y, Nishimura H, Kato S, Fujimoto K, Ohkuma K, Kojima K, Uchida M, Hayabuchi N. MRI of ganglioneuroma: histologic correlation study. J Comput Assist Tomogr. 2001;25(4):617-23.

11. Maciel CA, Tang YZ, Coniglio G, Sahdev A. Imaging of rare medullary adrenal tumours in adults. Clin Radiol. 2016;71(5):484-94.

12. $\mathrm{Xu} Y$, Wang J, Peng $\mathrm{Y}$, Zeng J. CT characteristics of primary retroperitoneal neoplasms in children. Eur J Radiol. 2010;75(3):321-8.

13. Lee JH, Chai YJ, Kim TH, Choi JY, Lee KE, Kim HY, Yoon YS, Kim HH. Clinicopathological features of ganglioneuroma originating from the adrenal glands. World J Surg. 2016;40(12):2970-5.

14. Shawa H, Elsayes KM, Javadi S, Morani A, Williams MD, Lee JE, Waguespack SG, Busaidy NL, Vassilopoulou-Sellin R, Jimenez C, et al. Adrenal ganglioneuroma: features and outcomes of 27 cases at a referral cancer centre. Clin Endocrinol (Oxf). 2014;80(3):342-7.

15. Luo L, Zheng $X$, Tao KZ, Zhang J, Tang YY, Han FG. Imaging analysis of ganglioneuroma and quantitative analysis of paraspinal ganglioneuroma. Med Sci Monit. 2019;25:5263-71.

16. Xie J, Dai J, Zhou WL, Sun FK. Adrenal ganglioneuroma: features and outcomes of 42 cases in a Chinese population. World J Surg. 2018;42(8):2469-75.
17. McCarville MB. Imaging neuroblastoma: what the radiologist needs to know. Cancer Imaging Off Publ Int Cancer Imaging Soc. 2011;11 Spec No A(1A):S44-47.

18. Monclair T, Brodeur GM, Ambros PF, Brisse HJ, Cecchetto G, Holmes K, Kaneko M, London WB, Matthay KK, Nuchtern JG, et al. The international neuroblastoma risk group (INRG) staging system: an INRG Task Force report. J Clin Oncol Off J Am Soc Clin Oncol. 2009;27(2):298-303.

19. Forsythe A, Volpe J, Muller R. Posterior mediastinal ganglioneuroma. Radiographics. 2004;24(2):594-7.

20. Linos D, Tsirlis T, Kapralou A, Kiriakopoulos A, Tsakayannis D, Papaioannou D. Adrenal ganglioneuromas: incidentalomas with misleading clinical and imaging features. Surgery. 2011;149(1):99-105.

21. lacobone M, Torresan F, Citton M, Schiavone D, Viel G, Favia G. Adrenal ganglioneuroma: the Padua endocrine surgery unit experience. Int J Surg. 2017:41(Suppl 1):S103-8.

22. Mylonas KS, Schizas D, Economopoulos KP. Adrenal ganglioneuroma: what you need to know. World J Clin Cases. 2017;5(10):373-7.

23. Otal P, Mezghani S, Hassissene S, Maleux G, Colombier D, Rousseau $\mathrm{H}$, Joffre F. Imaging of retroperitoneal ganglioneuroma. Eur Radiol. 2001;11(6):940-5.

24. Dayan D, Abu-Abeid S, Kuriansky J, Lahat G, Sagie B. Rare primary retroperitoneal neoplasms. Israel Med Assoc J. 2020;22(1):53-9.

25. Ozawa Y, Kobayashi S, Hara M, Shibamoto Y. Morphological differences between schwannomas and ganglioneuromas in the mediastinum: utility of the craniocaudal length to major axis ratio. Br J Radiol. 2014;87(1036):20130777.

26. Goenka AH, Shah SN, Remer EM. Imaging of the retroperitoneum. Radiol Clin North Am. 2012;50(2):333-55.

\section{Publisher's Note}

Springer Nature remains neutral with regard to jurisdictional claims in published maps and institutional affiliations.
Ready to submit your research? Choose BMC and benefit from:

- fast, convenient online submission

- thorough peer review by experienced researchers in your field

- rapid publication on acceptance

- support for research data, including large and complex data types

- gold Open Access which fosters wider collaboration and increased citations

- maximum visibility for your research: over 100M website views per year

At BMC, research is always in progress.

Learn more biomedcentral.com/submissions 